\title{
Editorial \\ Contextualization in Chinese Management Research
}

The need to 'contextualize' organizational studies is neither novel nor surprising. We have long paid attention to the context in studying phenomena within or about organizations (Blair and Hunt, 1986; Cappelli and Sherer, 1991; Mowday and Sutton, 1993; Porter, 1996; Rousseau and Fried, 2001). The reason is simple. Organizations or units within them are open systems, and that the context is a major source of influence must not be ignored or dismissed as scholars attempt to understand and explain the actions or behaviour of any unit. This seems obvious. Both scholars and managers know the importance of carefully managing the organization-environment linkage. However, the idea of contextualization goes beyond how a unit reacts to or interacts with its context. The manager of a US plant in China sees 'China' as the context, which she or he has to understand, navigate, and negotiate with. China is 'out there' while his or her firm is 'in here'. The manager, in other words, needs to either separate the company from outside influence or exploit and co-opt them for her company's benefits. This is not what I mean by contextualization. Contextualization means more than talking about environmental opportunities and constraints that managers either exploit or are victimized by. Rather than seeing the firm as one entity and the context or environment as 'out there', we see the context and contextualization as much more.

So, what is the 'much more'? I cannot provide an exhaustive discussion of the meaning of the term 'context' but will offer a few illustrative examples. For example, at the individual level it is cognitions (sense-making, heuristics, thought processes, linguistic habits, attributions, etc.). At the institutional level it is the way role relations are organized. Friedland and Alford (1991) argue that there are different logics (material practices and symbolic constructions) that are particular to different domains or institutional sectors (the state, economy, family, education, science, etc.). At the larger societal level we have values and beliefs that are created, interpreted, and reproduced through the governments, mass media, religions, and educational systems. Lastly, there is serendipity, for example, accidents, scandals, 
discoveries, wars, revolutions, droughts, and so on, which affect the course of history. In other words, the context includes the culture, the political and legal system, the stage of economic development, or the economic system at one point in time. It also includes the history, the geography, its ecology, and all that has transpired over time and in space that have produced what and why a context is the way it is today. Contextualization means incorporating the context in describing, understanding, and theorizing about phenomena within it. In fact, because of the multiplicity of the context, the word 'polycontextualization' has been introduced (Von Glinow, Shapiro, and Brett, 2004) to describe the process of incorporating multiple dimensions of a context for a holistic and valid understanding of any phenomena within it.

The paper by Rousseau and Fried (2001) in a special issue of the Fournal of Organizational Behavior entitled 'Location, location, location: Contextualizing organizational behavior research', offers an excellent discussion of the idea of contextualization along the line suggested here. They identified features of the context that need to be considered in contextualizing organizational research. They highlighted three tiers of contextualization, from thick descriptions of the context to direct analysis of the effect of context on the phenomenon under study, and comparative studies by identifying common and unique features across contexts. They drew examples from and discussed implications for both domestic (aka USA) and international management research. In this editorial, I will focus specifically on contextualization in Chinese management research. I will elaborate on the 'much more' by discussing four areas of contextualization and providing some suggestions on how to contextualize in each area. I will not discuss the 'why', assuming that the need for contextualization is well accepted and its potential benefits are well understood. I will focus on the 'how', and offer some simple guidelines on how to pursue (1) contextualization in choosing the phenomena to study, (2) contextualization in developing the theory to explain the phenomenon, (3) contextualization in measurement, and (4) contextualization in methods. Some of the ideas in this editorial have been discussed in Tsui (2004) and other sources (e.g., Rousseau and Fried, 2001; Whetten, 2002a). This short editorial is a contextualization of these ideas to Chinese management research.

\section{GONTEXTUALIZATION OF THE PHENOMENA - FROM 'OUTSIDE IN' TO 'INSIDE OUT'}

Simply put, this is about 'what to study'. My observation and reading of the research on China ( $\mathrm{Li}$ and Tsui, 2002; Tsui, Schoonhoven, Meyer, Lau, and Milkovich, 2004) suggests that there are two general types of research questions being pursued. One is to directly ask a commonly studied question in, or apply a familiar phenomenon to, the Chinese context. Studies on conflict management, negotiations, decision-making, leadership, strategy, innovation, knowledge trans- 
fer, or organizational learning are typical examples. These phenomena are familiar to Western scholars and have a large scholarly community that the authors of Chinese studies could join. This is a relatively risk-free approach because the author can build upon a well-established body of literature and utilize wellaccepted methods. This is also useful for the new knowledge to be understood and acceptable to the larger (aka Western) scholarly community. This approach is consistent with the recommendation of Whetten (2002a) that Chinese management scholars can contribute to the global management knowledge by 'using the familiar to describe the new' (p. 33) or 'using the new to describe the familiar' (p. 35). In this type of research, the authors relate the novelty of the new context to the literature familiar to the Western readers by studying the phenomena commonly found in Western contexts and familiar to the Western scholars.

The above is an 'outside in' approach in selecting the phenomena to study in China. The scholars choose popular topics or phenomena in the existing literature and examine how they are manifested in the Chinese context. It is a literature-driven approach in defining what to study in the new Chinese context. This approach, however, while useful to connect to the literature, carries the serious possibility of missing the truly important management or organization issues in the Chinese context. I advocate and argue for an 'inside out' approach, identifying the important issues that are unique or at least important to Chinese firms, managers, and employees, even if such phenomena might be foreign to scholars outside this context. There are some good examples of such 'inside out' research in the Chinese management literature. These include studies on the transition from a planned to a market economy (Nee, 1989, 1991, 1996), tracking career mobility (Bian, 1997; Walder, 1995) or job shift patterns (Zhou, Tuma, and Moen, 1997) as a result of market transition, identifying new or alternative organizational forms (Boisot and Child, 1988, 1996; Nee, 1992), discussing the problems of property rights ambiguity (Walder, 1992), and analysing changes in reward allocation preference by Chinese workers (Chen, 1995), just to list a few examples. The authors of these studies are interested primarily in understanding the unique issues within this dynamic context, and secondarily in comparing China to other contexts. Studies of these context-specific phenomena can add valuable and novel insight to the stock of global management knowledge.

Obviously, the 'inside out' approach requires an in-depth knowledge of the context. Scholars studying context-specific phenomena should have a deep knowledge of China. Most of them have gained this knowledge by spending substantial amounts of time in observing and interacting with local scholars or managers, or working with collaborators who have intimate knowledge of the context. Many of them visit China frequently and converse with local managers extensively and intensively. Such close encounters allow them to do a good 'needs assessment' of the important issues from the Chinese managers' perspective. Many of the methods in the Sage book, What to Study, by Campbell, Daft, and Hulin (1982) 
might be adapted by Chinese management scholars in identifying the meaningful research questions to address. The methods include reading popular magazines and newspapers for critical management issues observed by the news media, talking with managers and employees in the executive education classrooms, discussing with management consultants who are called to provide advice and solve problems for foreign or domestic firms, and conversing with Chinese scholars who often consult and lecture in Chinese companies. More importantly, I recommend engaging in participant and non-participant observation inside organizations in order to acquire a first-hand knowledge of daily challenges and areas of tension inside these firms. This 'grounded' approach might unveil critical issues that are not transparent to the casual or unattached observers. There is the possibility of discovering problems or phenomena that may not be readily familiar to Western scholars or revealing concepts or topics not found in the extant literature: In general, the potential of studying important and relevant issues in China would have a much greater potential to make meaningful contributions to the global management literature in general and to Chinese management knowledge in specific. To borrow a Chinese idiom, the advice of 'plunging into the sea' (tiao jin da hal) rather than fishing from ashore is worthy of serious consideration by scholars interested in addressing issues of real significance to firms operating in the Chinese context and discovering knowledge of real value to these firms.

\section{CONTEXTUALIZATION IN THE THEORY - FROM 'APPLICATION' TO 'CREATION'}

Another common approach that I have observed over the years in studies of Chinese management research is the direct application of Western theories to the Chinese context. This is an excellent first step and a reasonable approach to ensure 'connection' to the existing body of knowledge, and it certainly is better than no theory. The potential problem in this approach is that the observation and the analysis are constrained to the variables included in the existing theory and the logic underlying the theory. Western theories are founded on a set of assumptions and logic that are particular to Western cultural and institutional underpinnings. For example, equity theory is based on the intra-personal input-output balance and social comparison with others doing similar work. To the extent that the concept of fairness has different etiological basis (e.g., what is fair in one context may be unfair in another context), application of this theory to a new context may result in meaningless predictions at best and erroneous predictions at worst. Let me further elaborate using this simple example. Treating everyone the same is fair in a collectivistic culture, but is unfair in an individualistic culture. The underlying cultural assumption of the collectivistic context is that any outcome is the fruit of the group to which the individual belongs. No one member can take sole credit for any outcome, even if the outcome was the result of the action of a single indi- 
vidual. This community attribution of outcomes influences a conception of fairness that may be drastically different from that in another context where attribution of outcomes is to the person even when teams are emphasized (e.g., our team succeeds because of Joe). Of course, there are nuances to this theory, but the point I wish to make is that the application of a theory developed in the Western context must be contextualized when used to analyse a related phenomenon in the Chinese context.

Accurate contextualization of the theory requires an accurate knowledge of the cultural assumptions of both the original and the new context. Based on earlier studies of the Chinese culture (Hofstede, 1980), Chinese people are considered to be collectivistic, while Americans to be individualistic. When comparing reward allocation preferences, it would be reasonable to hypothesize that Chinese people would prefer the equality rule while Americans would prefer the differential rule. However, based on his deep knowledge of the changes in China and the goal priority of the organizations in the reform era, Chen (1995) hypothesized that the contemporary Chinese people would prefer differential rules for allocating both materialistic and socio-emotional rewards. On the other hand, his observations of the push for humanism in American organizations suggest that there may be changes in the allocation criterion preferred by Americans for some rewards while the value of meritocracy may remain for other rewards. Therefore, Chen hypothesized that Americans would prefer the equality rule for allocating socio-emotional rewards but the differential or performance rule for allocating materialistic rewards. These non-intuitive hypotheses reveal a keen knowledge of both contexts and a relevant contextualization of the concept of fairness. By contextualizing the theory, Chen was able to enhance the validity of the theory in the new context, derive counterintuitive hypotheses, and increase the predictive accuracy of the theory.

A recent update of the Chinese management research literature (Tsui et al., 2004) reported that most of the studies published between 2000 and 2003 continued to be tests of existing management theories. Popular theories utilized include institutional, agency, resource-based, and stewardship theories, transaction cost economics, cultural distance, and competitive versus cooperative dynamics at the macro or firm level. At the micro or individual level, theories used in the studies reviewed include role theory, justice theory, and cultural diversity. This review identified two new theories and only one was based on a grounded theory-building methodology. The paucity of inductive theory-building research may be hampering the advancement of Chinese management knowledge. Given China's unique social, cultural, historical, and political mosaic, there is a need to explore the possibility of unique Chinese organizational and management models. The field of Chinese management research direly needs more theory-building studies and less pure application of Western theories, which is similar to the 'outside in' approach of choosing what phenomenon to study. 
Grounded theory-building requires skills in abstracting generalizations from vast amounts of qualitative and quantitative data with highly context-embedded meanings. Both local knowledge and conceptual capacity are necessary for developing locally valid theories and models. Whetten (2002b) offers useful guidelines on developing theoretical models. It begins with becoming very familiar with the data (observations, qualitative, or quantitative) and then drawing boxes (for observable constructs), circles (for unobservable or mediating constructs) and arrows (connection between constructs) to achieve a reasonable approximation of the data. Once a preliminary picture is attained, the next step is in justifying the choice of these boxes and circles and articulating the logic underlying the linkages. It is an iterative process involving going back and forth between the 'picture' and the 'data', as many times as needed, until clarity is achieved and one is fully satisfied with both the picture and the explanation for it. What constructs are suggested by the data? What data can support the constructs? Should the arrow go to another box or circle or should the arrow be reversed? What factors would change the strength or direction of the relationship between two constructs? This is to identify potential moderators. Of all the boxes and circles, which is the most important and novel? Would the picture be more or less interesting or meaningful if one box or circle (a construct) is deleted? Developing a theory is like an artist creating a visual image that reveals a phenomenon that is surprising, intriguing, and delighting. As Weick (1995) said, a good theory both informs and delights the audience.

There are several fine examples of contextualization in theory through the inductive process in Chinese management research. This essay is not intended to provide an exhaustive literature review. Therefore, I will use two examples that I am familiar with for illustration. They are the studies by Boisot and Child (1988, 1996) and a more recent study by Meyer and Lu (2005). Max Boisot and John Child spent a substantial amount of time in China and both lived there for several years in the mid-1980s. Through their keen observation and astute analysis, they concluded that 'the limited extent of codification of information in China and its communal property rights and organization of economic transactions suggest that decentralization from former state command system is giving rise to a distinct institutional form - network capitalism' (1996, p. 4). Marshall Meyer's interest in China began in spring 1996 when he spent a short sabbatical at the Hong Kong University of Science and Technology. Since then, he has been travelling to China several times a year in order to study and understand the strategy and structure of Chinese firms. In the 2005 article published in the inaugural issue of Management and Organization Review, he and Xiaohui Lu reported their analysis of a company's structure that would horrify any executive of a Western company. They wrote, 'Tacitly, most researchers view organizations as bounded, tightly coupled and more or less rational systems ... In the case of China, incomplete separation of firms from the state, incomplete integration of firms and partial listing of assets have left most Chinese firms with indefinite boundaries' (2005, p. 57). Clearly, this 
lack of definition in the boundaries of some of the Chinese organizations is a result of the transition from one form of ownership to another form in the vacuum of well-defined legal and institutional rules. This study highlights the need for contextualization in the conceptual definition of ownership and associated theory.

Pure replication of Western studies and retesting of existing theories in China is a useful learning experience appropriate for doctoral students. To develop new knowledge, extended replication (Tsang and Kwan, 1999) is a good starting point. To date, most contributions to Chinese management research have been from extended replication studies (e.g., Luo and Peng, 1999; Yan and Gray, 1994). Discovery of valuable and delightful knowledge will come from major breakthroughs in understanding the logic of managing and organizing in the Chinese context. This will require inductive grounded theory building. $M O R$ would like to publish more theory-building studies that will contribute to the development or discovery of Chinese management models eagerly awaited for by the scholarly community and practising managers. The time is ripe for such endeavours and I encourage authors to 'plunge into the sea' and catch new fish, rather than be limited to the use of current species to describe a new beast. Somewhat differently: we encourage inductive, theory-building research drawing upon or extending Western management concepts to the Chinese context, but ultimately through creating new theories that could be only discovered by looking through a completely different lens.

\section{CONTEXTUALIZATION IN MEASUREMENT - FROM 'TRANSLATION' TO 'INDIGENIZATION'}

Simply put, this is about 'construct validity'. All the procedures required in developing valid measures (e.g., Hinkin, 1995) and criteria for assessing construct validity (e.g., Bagozzi, Yi, and Phillips, 1991; Schwab, 1980) apply when developing new measures for research in the Chinese context. Interestingly, there is a paucity of new measures, but a loyal use of existing measures taken from the published (Western) literature. Using existing proven measures is good advice in general. Most of the efforts to ensure measurement quality in Chinese management studies have focused on accurate translation to ensure construct equivalence. Items from existing measures are translated into Chinese by one bilingual researcher and then back-translated into English by a different bilingual researcher. The original English statements are compared to the back-translated statements and any differences are reviewed. Changes in the Chinese translation are made to improve the similarity in meaning between the back-translated and original statements. This back-translation procedure (Brislin, 1981) is a well-accepted convention that guides Chinese management research. A recent book by Behling and Law (2000) expanded on the Brislin procedure by offering additional procedures to further refine the translation process in achieving four types of equivalence: conceptual, semantic, normative, and measurement. However, as Behling and Law (2000) 
explained, while accurate translation is important and necessary, it is not sufficient for valid measurement in a new context. More serious attention to contextualization is desirable for valid measurement, and I refer to this serious attention as 'indigenization', similar to the word 'localization' in the world of practice.

Indigenization of measurement occurs at two levels. The first level is in ensuring the Western-developed construct is meaningful in the Ghinese context. This is especially important for psychological constructs whose meaning is affected by the social and cultural tradition. For example, what does motivation mean in China? What about the concepts of fairness, conflict, or trust in the workplace? In an exemplary study by Farh, Earley and Lin (1997), they adopted Organ's (1988) definition of organizational citizenship behaviour. They provided the (Western) definition to the Chinese employees in their sample and asked them to identify behaviours in their companies (in Taiwan) that would fit the definition provided. In a later study in mainland China, Farh and his colleagues (2004) aimed to identify a measure of organizational citizenship behaviour in the mainland Chinese context, using the same definition and study procedure as was used in the Taiwan study. They developed a set of behavioural indicators of organizational citizenship behaviour that differ somewhat from those found in Taiwan as well as from those in the existing (Western) literature. The process of identifying locally meaningful indicators used by Farh et al. (1997) is rigorous and flawless. Yet, I cannot help but wonder if the results of their study would differ if they had also 'indigenized' the meaning or definition of the construct, which originated in a different institutional context. The answer is probably not, since the respondents in both contexts readily accepted the definition provided by Farh. Nonetheless, identifying local meaning of prevalent constructs seems to be a desirable step in ensuring a high level of construct validity in Chinese management research.

The second level of indigenization is exactly what Farh et al. (1997), and also several other studies familiar to me, did. They include the concept of organizational culture by Xin and her colleagues (2002), the concept of leadership style (Tsui, Wang, Xin, Zhang, and Fu, 2004), and the concept of employment relationship in the dissertation research by Wang (with Tsui, Zhang, and Ma, 2003). In each case, the process began with presenting a construct and its current definition to the Chinese respondents. The respondents were asked if the construct was understandable, and whether they could relate to or had observed the phenomenon described by the construct in their daily work. After affirmation, the respondents provided examples of behaviours or indicators that relate to the constructs in an open-ended questionnaire or in a semi-structured interview. The statements were content analysed by two or three independent judges who were usually doctoral students in management. The categories emerged were discussed and consolidated, and representative items were identified for each category. A written survey was developed and a large sample used for an exploratory factor analysis, followed by another sample for a confirmatory factor analysis. Since the measures 
were applied to only the Chinese sample, measurement equivalence (between two or more culturally different samples) was not necessary. The outcomes of these efforts are usually a set of measures that include some dimensions similar to those found in the existing (Western) literature and some dimensions unique to the local context. Farh et al. (1997) used the term 'etic' to refer to the former and the term 'emic' to refer to the latter.

The identification of different indicators of the construct, while useful and meaningful for context-specific research, would pose challenges for cross-cultural or comparative research. Current analytical approaches (e.g., multi-group SEM) do not allow for tests of measurement equivalence when a measure involves different indicators. Other methods of evaluating construct equivalence without statistical equivalence will be necessary as scholars continue to find different indicators for the same (Western-derived) constructs in China. Continuing efforts on contextualization in theory development may lead to the possible emergence of new constructs (e.g., the concept of pao in the recent article on particularistic and general trust by Luo, 2005, volume 1, issue 3 of $M O R$ ). Is pao identical with the concept of reciprocity, which Gouldner (1960) proposed to be universal? Future research may compare the concept of pao to equivalent concepts in other contexts. This is the process of 'reverse exporting' of concepts (using pao to study related concepts in other contexts) discussed by White (2002).

To further Chinese management research and develop valid knowledge, contextualization in measurement is not only desirable, but essential. For this reason, MOR sponsored a special issue on 'Developing Valid Measures in Chinese Management Research'. The submissions to that special issue are currently in the review process, and I look forward to publishing some outstanding papers that will serve as models for more research on this important topic. Again, there is merit in the advice of 'plunging into the China sea' and studying the marine biology as the indigenous fishermen do, rather than relying on concepts descriptive of waters far from the Chinese shores.

\section{CONTEXTUALIZATION IN METHODOLOGY - FROM 'SHARPENING OLD TOOLS' TO 'DEVELOPING NEW INSTRUMENTS'}

Now I come to the most challenging of the four areas of contextualization, which is the uncertainty in the relevance of our current research methods, and the set of tools for observing, recording, and analysing data from and in the Chinese context. The current methods used by the Western scholars include the paper-and-pencil survey (including the modern Internet version), the laboratory experiment, interviews, participant or non-participant observation, and the use of archival data or unobtrusive measures. Research has shown that Chinese people are modest, and avoid taking extreme actions or stating extreme positions. How would such a 
tendency influence their responses in written surveys or in personal interviews? Chinese people also emphasize 'face', and thus avoid direct criticism or explicit refusal of any requests. Furthermore, deference to authority may lead them never to refuse a request from a professor or anyone in a position of authority. Instead, they would comply in a modest manner. How would these tendencies influence the quality of the data they provide? As a high context culture, Chinese people are sensitive to their social environment, and thus may be more susceptible to social cues. Would there be a greater likelihood of 'shared mental models' among Chinese people than among a group of Westerners? Would these tendencies reduce the variance in the data and suppress the true variance in individual differences on the concept of interest? Might there be more common method variance with the tendency to avoid extremes and the presence of shared mental models among employees in the same organization? The potential limits of current data-gathering and observation methods should be studied to identity how and where contextualization in research methods is necessary and desirable.

Thus far, the methods used in published Chinese management research have all been those used by Western scholars. Ironically, IACMR conducted a research methods class in Xi'an in July 2005, where we introduced the most commonly used methods to our Chinese colleagues and graduate students. Are we doing our Chinese friends a disservice by introducing them to methods that may limit the quality of their data and observations? Fortunately, we can easily justify the need for such training because our Chinese friends need to understand the methods used in the (Western) literature that they are reading, learning, and imitating. Such training is necessary for knowledge transfer, because it improves the readers' absorptive capacity. Also, imitation is an excellent first step in knowledge transfer and knowledge creation. We encourage our Chinese colleagues to be familiar with the current sets of methods. An intimate knowledge of the current tools should facilitate the creation of new methods as Chinese scholars accumulate experience about the constraints of existing tools.

Let me return to the metaphor of a fisherman (or fisherwoman). Contextualization in methods means the modification of existing fishing tools and the creation of new fishing instruments. I encourage the development of research methodology as an area of specialization among our Chinese management scholars, along the line of the Research Methods Division in the Academy of Management. $M O R$ would be interested in the idea of a special issue on 'Developing Valid Methods in Chinese Management Research'. The editorial team of MOR would welcome a proposal on this topic, along with submissions of studies on contextualized theory-building and measurement validation, focusing on unique issues about management and organizations in the Chinese context.

I would like to conclude with an invitation to an interdisciplinary assault on the problem of contextualization. It seems that psychologists, sociologists, historians, anthropologists, and even economists can help address the problem of doing 
research on China. Beyond organizations and management, studies of personality, political attitudes and behaviour, collective action, job mobility, 'happiness,' population, and family-rearing practices certainly would have the same challenge to contextualize their theories, measurement, or even methods. Even for the same issue, each discipline uses a different lens to observe and describe it, but through describing to other disciplinary colleagues what they see and why they see what they see, collectively we may come to a better and more 'accurate' understanding of the Chinese phenomena.

I further encourage continuing dialogues and collaboration between behavioural and social scientists both within and outside China. I am not sure that our scholars inside China are necessarily better able to contextualize their research concepts, models, or methods. It is like fish in water. They may have taken the water for granted. Outsiders can question the assumptions and help the insiders to articulate their experiences and sources of these experiences by asking questions that would never be asked by the insiders themselves. Outsiders can also improve their understanding of the Chinese experiences by plunging into the Chinese waters as I have repeatedly emphasized. Chinese scholars should be encouraged to step ashore and reflect on their experiences after they are detached from the context (e.g., through visiting positions abroad in their collaborator's institutions). Cross-cultural collaboration seems to be not only desirable but essential for success in contextualization. It is for this reason that the International Association for Chinese Management Research was created, to facilitate the exchange of research ideas and experiences across borders and the formation of research collaboration between the scholars within and outside China. The editorial team at Management and Organization Review looks forward to seeing the fruits of such interdisciplinary and cross-cultural collaborations through manuscripts that reflect more and better contextualization in the studies of Chinese organizations, management, and work experiences.

\section{NOTE}

I would like to thank Joseph Galaskiewicz, Marshall Meyer, and Yadong Luo for their helpful comments and suggestions on an earlier draft of this editorial essay.

\section{REFERENGES}

Behling, O. and Law, K. S. (2000). Translating Questionnaires and other Research Instruments - Problems and Solutions. Thousand Oaks, CA: Sage.

Bagozzi, R. P., Yi, Y. and Phillips, L. W. (1991). 'Assessing construct validity in organizational research'. Administrative Science Quarterly, 36, 42 1-48.

Bian, Y. (1997). 'Bringing strong ties back in: Indirect ties, network bridges, and job searches in China'. American Sociological Review, 62, 266-85.

Blair, J. D. and Hunt, J. G. (1986). 'Getting inside the head of the management researcher one more time: Context-free and context-specific orientations in research'. Fournal of Management, 12, $147-66$. 
Boisot, M. and Child, J. (1988). 'The iron law of fiefs: Bureaucratic failure and the problem of governance in the Chinese economic reforms'. Administrative Science Quarterly, 33, $507-27$.

Boisot, M. and Child, J. (1996). 'From fiefs to clans and network capitalism: Explaining China's emerging economic order'. Administrative Science Quarterly, 41, 600-28.

Brislin, R. W. (1981). Translation and content analysis of oral and written material. In Triandis, H. C. and Berry, J. W. (Eds.), Handbook of Cross-cultural Psychology (Vol. 1, pp. 389-444). Boston: Allyn \& Bacon.

Campbell, J. P., Daft, R. L. and Hulin, C. L. (1982). What to Study: Generating and Developing Research Questions. Thousand Oaks, CA: Sage.

Cappelli, P. and Sherer, P. D. (1991). 'The missing role of context in OB: The need for a meso-level approach'. Research in Organizational Behavior, 13, 55-110.

Chen, C. C. (1995). 'New trends in reward allocation preferences: A Sino-U.S. comparison'. Academy of Management Fournal, 38, 408-28.

Farh, J. L., Zhong, C. B. and Organ, D. W. (2004). 'Organizational citizenship behavior in the People's Republic of China'. Organizational Science, 15, 241-53.

Farh, J. L., Earley, P. C. and Lin, S. C. (1997). 'Impetus for action: A cultural analysis of justice and organization citizenship behavior in Chinese society'. Administrative Science Quarterly, 42, $421-44$.

Friedland, R. and Alford, R. (1991). 'Bring society back in: Symbols, practices, and institutional contradictions'. In Powell, W. and DiMaggio, P. (Eds.), The Nere Institutionalism in Organizational Analysis. Boston: Allyn \& Bacon, (pp. 232-63).

Gouldner, A. W. (1960). 'The norm of reciprocity'. American Sociological Review, 25, 161-78.

Hinkin, T. R. (1995). 'A review of scale development practices in the study of organizations'. Journal of Management, 21, 967-88.

Hofstede, G. (1980). Culture's Consequences: International Differences in Work Related Values. Beverly Hills, CA: Sage.

$\mathrm{Li}$, J. T. and Tsui, A. S. (2002). 'A citation analysis of management and organization research in the Chinese context: 1984-1999'. Asia Pacific Journal of Management, 19, 87-107.

Luo, J. D. (2005). 'Particularistic trust and general trust: A network analysis in Chinese organizations'. Management and Organization Review, 1, 3, 437-58.

Luo, Y. and M. W. Peng. (1999). 'Learning to compete in a transition economy: Experience, environment, and performance'. Fournal of International Business Studies, 30, 2, 269-96.

Meyer, M. W. and Lu, X. H. (2005). 'Managing indefinite boundaries: The strategy and structure of a Chinese business firm'. Management and Organization Reviere, 1, 57-86.

Mowday, R. T. and Sutton, R. I. (1993). 'Organizational behavior: Linking individuals and groups to organizational contexts'. Annual Review of Psychology, 44, 195-229.

Nee, V. (1989). 'A theory of market transition: From redistribution to markets in state socialism'. American Sociological Review, 54, 663-81.

Nee, V. (1991). 'Social inequalities in reforming state socialism: Between redistribution and markets in China'. American Sociological Review, 56, 267-82.

Nee, V. (1992). 'Organizational dynamics of market transition: Hybrid forms, property rights, and mixed economy in China'. Administrative Science Quarterly, 37, 1-27.

Nee, V. (1996). 'The emergence of a market society: Changing mechanisms of stratification in China'. American fournal of Sociology, 101, 908-49.

Organ, D. W. (1988). Organizational Citizenship Behavior: The Good Soldier Syndrome. Lexington: MA: Lexington Books.

Porter, L. W. (1996). 'Forty years of organization studies: Reflections from a micro perspective'. Administrative Science Quarterly, 41, 262-69.

Rousseau, D. M. and Fried, Y. (2001). 'Location, location, location: Contextualizing organizational research'. Journal of Organizational Behavior, 22, 1-13.

Schwab, D. P. (1980). 'Construct validity in organization behavior'. In: Staw, B. M. and Cummings, L. L. (Eds.), Research in Organizational Behavior. Greenwich, CT: JAI Press, (Vol. 2, pp. 3-43).

Tsang, E. W. and Kwan, K. M. (1999). 'Replication and theory development in organization science: A critical realist perspective'. Academy of Management Review, 34, 759-80.

Tsui, A. S. (2004). 'Contributing to global management knowledge: A case for high quality indigenous research'. Asia Pacific Journal of Management, 21, 491-513. 
Tsui, A. S., Schoonhoven, C. B., Meyer, M. W., Lau, C. M. and Milkovich, G. T. (2004). 'Organization and management in the midst of societal transformation: The People's Republic of China'. Organization Science, 15, 133-44.

Tsui, A. S., Wang, H., Xin, K., Zhang, L. H. and Fu, P. P. (2004). " "Let a thousand flowers bloom": Variation of leadership styles among Chinese CEOs'. Organizational Dynamics, 33, 5-21.

Von Glinow, M. A., Shapiro, D. L. and Brett, J. M. 2004. 'Can we talk, and should we? Managing emotional conflict in multicultural teams'. Academy of Management Review, 29, 4, 578-92.

Walder, A. G. (1995). 'Career mobility and the communist political order'. American Sociological Reviere, 60, 309-28.

Walder, A. G. (1992). 'Property rights and stratification in socialist redistributive economies'. American Sociological Review, 57, 524-39.

Wang, D. X., Tsui, A. S., Zhang, Y. C. and Ma, L. (2003). 'Employment relationships and firm performance: Evidence from an emerging economy'. Fournal of Organizational Behavior, 24, 511-35.

Weick, K. E. (1995). 'What theory is not, theorizing is'. Administrative Science Quarterly, 40, 385-90.

Whetten, D. A. (2002a). 'Constructing cross-context scholarly conversation'. In Tsui, A. S. and Lau, C. M. (Eds.), The Management of Enterprises in the People's Republic of China. Boston, MA: Kluwer Academic, (pp. 29-47).

Whetten, D. A. (2002b). 'Modeling-as-theorizing: A systematic methodology for theory development'. In Partington, D. (Eds.), Essential Skills for Management Research. London, UK: Sage (pp. $45-71$ ).

White, S. (2002). 'Rigor and relevance in Asian management research: Where are we and where can we go?' Asia Pacific Journal of Management, 19, 287-353.

Xin, K. R., Tsui, A. S., Wang, H., Zhang, Z. X. and Chen, W. Z. (2002). 'Corporate culture in Chinese state-owned enterprises: An inductive analysis of dimensions and influence'. In Tsui, A. S. and Lau, C. M. (Eds.), Management of Enterprises in the People's Republic of China. Boston, MA: Kluwer Academic, (pp. 415-444).

Yan, A. and Gray, B. (1994). 'Bargaining power, management control, and performance in United States-Chinese joint ventures: A comparative study'. Academy of Management Fournal, 37, 6, 1478-1517.

Zhou, X., Tuma, N. B. and Moen, P. (1997). 'Institutional change and job-shift patterns in urban China, 1949 to 1994'. American Sociological Reviere, 62, $339-65$.

Anne S. Tsui

Editor-in-Chief 